I agree that confidence intervals are valuable indicators of the precision of a sample estimate and if I were writing the paper today I would include these as a matter of routine. Undoubtedly, a larger sample of patients would have led to narrower confidence intervals and allowed us to test other hypotheses about traditional ECT. As we explained in the paper, this would also have exposed more depressed patients to a treatment known to be associated with more severe confusion, anterograde amnesia and, to a lesser extent, a greater risk of the loss of personal memories.

Gardner, M. J. \& Altman D. G. (1989) Statistics with Confidence, p4. London: British Medical Journal.

SCOTt, A. I. F., WhalLeY, L. J., BenNIE, J. P., et al (1986) Oestrogenstimulated neurophysin and outcome after electroconvulsive therapy. Lancet, i, 1411-1414.

Royal Edinburgh Hospital

A. I. F. ScotT

Morningside Terrace

Edinburgh EHIO $5 \mathrm{HF}$

\section{Daily living programme}

SIR: Muijen et al's preliminary account of an intensive community support scheme as an alternative to prolonged or revolving-door hospital admissions made interesting reading (Muijen et al, Journal, March 1992, 160, 379-384). They rightly draw attention to the worrying finding that the study group in the Daily Living Programme included two patients who later killed themselves and another man charged with murder. In assessing such treatment programmes we must, of course, bear in mind that other such controlled studies have not attracted such tragedies and so it would be unwise to draw general conclusions about the worthiness or desirability of such a programme.

However, it would be valuable to have further information regarding these three violent episodes. One wonders about their diagnoses, severity of illness and although contact was 'regular', was it frequent and of what kind was it? How early in the treatment programme did the events occur and if early on, were mean figures added in (to cover for the rest of the treatment phase as if the suicides were still included) on the assumption that the suicides were a tragic, but random event?

While such programmes are in an early phase and before they are generally introduced we need to ensure that such unfortunate events were indeed random (and not dependent upon whether a patient is assigned to a hospital or community treatment group). Any cost-savings of such a community treatment package (if as well run as the Maudsley's) seem to be slight, and the justification may, therefore, rest on qualitative rather than quantitative factors.

Department of Psychiatry

BEN GREEN

Royal Liverpool Hospital

PO Box 147

Liverpool L69 3BX

AUTHOR's REPLY: Dr Green asks about the tragedies in our study. Among our 187 Daily Living Programme (DLP) patients and controls seen for 18 months after trial entry, the DLP had three, and the control group two, deaths from self-harm. The deaths were 4, 5 and 14 months after trial entry; all had had brief in-patient stays. The control deaths were 7 and 12 months after trial entry following admissions of 4 and 3 months' duration. The difference of three versus two deaths does not begin to approach statistical significance. (Further details will appear in our final report.)

Many studies have noted a high suicide rate in psychotic patients, and there is no easy way to reduce this. The risk remains high despite intensive inpatient and/or community care. When monitored, suicides occur surprisingly often even in patients on section and on 24-hour 'special' observation by nurses. There is no evidence as yet that standard in-patient care actually reduces suicide rates in the long-term. Evaluation has to be even-handed between innovative and standard models of care. It rarely is.

The DLP patient's homicide took place more than seven weeks after admission for self-cutting. During five days of in-patient observation he was wary but coherent and rational. Repeated examination found no signs of depression or psychosis. With the ward team's agreement he was discharged into intensive community care, and was seen repeatedly at his home and the DLP base despite his evasiveness. He managed well, and was found a job after having been unemployed for several years. He had not been sectionable at any time. Two days after last being seen he suddenly killed a child. In custody he revealed previously concealed paranoid delusions.

Had the above patient remained an in-patient well beyond the national mean duration for such cases he could have discharged himself, been lost to outpatient follow-up, and become an ex-patient for whom district services could disclaim responsibility. Community care teams like the DLP which rightly do assertive outreach, however, continue their responsibility and thus their vulnerability to blame for adverse events. With whom does the responsibility 